\title{
The Cognitive Psychology of Belief in the Supernatural
}

\author{
Belief in a deity or an afterlife could be an evolutionarily advantageous by- \\ product of people's ability to reason about the minds of others
}

\author{
Jesse M. Bering
}

$\mathrm{O}^{\mathrm{r}}$ ne hot summer day several years ago, I lay holed up in a suffocating Fort Lauderdale hospital roomthe result of an especially virulent bout of the flu. Having nothing but the buzzing of dying flies and the sound of muted television game-show applause to engage my interest, I turned my attention to the doleful lamentations of my elderly roommate, a handsome Navy veteran from World War II with a painfully defunct hip and, I gathered, an even more painful theological crisis on his hands. It seems that he had been yanked from the bedside of his aged wife, and he feared that she'd die without him being there. To make matters worse, he had the sneaking suspicion that his son wanted to jettison him off to a nursing home after her death, away from their cherished house and the beautiful garden they'd cultivated for the last 20 years. "I don't understand why God is doing this," he protested meekly to a sympathetic young nurse. "We've always been good people, my wife and me. What did we do to deserve this?"

That's strange, I thought. Didn't I ask the same thing just the other day as I was crawling about on the bathroom floor, expelling bodily fluids that I didn't even know I had in me? Indeed, I could

Jesse M. Bering received his Ph.D. in developmental psychology from Florida Atlantic University. He is currently an assistant professor of psychology at the University of Arkansas and is an international fellow at the Institute of Cognition and Culture of the Queen's University Belfast. His research interests include intuitive perceptions of the afterlife, folk psychologies of souls, and the concepts of meaning and destiny. Address: Department of Psychology, University of Arkansas, Fayetteville, AR 72701. Internet: jbering@uark.edu distinctly recall the feverish mantra: "Oh, God, please, no more!" And I'm not particularly religious. Just what was this connection between suffering and God all about, anyway?

This observation got me thinking about other existential experiences. The same way that I couldn't help thinking of God under dire circumstances, I've also found that I can't fathom what it would be like not to have an afterlife. I'm a materialist-I think consciousness ends with death. But nonetheless, try as I might, I run into a brick wall whenever I attempt to imagine what it would be "like" to be dead and not exist. I doubt I'm the only one. In the United States, as much as 95 percent of the population reportedly believes in life after death.

At least from a purely naturalistic perspective, one where we properly view ourselves as animals, such religious beliefs are an odd sort of thing. Not many people would classify their beliefs in God or heaven as "supernatural," even though that's precisely what they are. Just what is it about the human mind that leads so many members of our species, across cultures and geographic distances, to hold such an unshakable, sober and highly personal belief in an invisible, all-powerful being whom Westerners call God? On the face of it, this invisible being is a voyeur who knows all about you, an aloof sadist (as some people believe in the wake of personal misfortunes), a sexual totalitarian and a personal friend, all rolled into one. The fact that, normally, none of this strange mix seems to strike us as bizarre may indicate that this trait has somehow had a deeper benefit for our species.

Mere desire to believe (or, using Sigmund Freud's term, wish fulfillment) doesn't seem to cut it as an explanation of these traits. In studies I have conducted, people's levels of death anxiety didn't have much correlation with their types of religious beliefs-those with low fear of dying, for instance, are just as likely to be materialists as they are immortalists (who believe in consciousness after death). Religious beliefs could instead be a result of cultural indoctrination, a simple matter of exposure from birth to such ideas. But maybe it goes back even further than birth: Perhaps human minds have a genetic predisposition toward supernatural belief.

To some, these questions are distasteful, even silly, because they suggest that God and the afterlife are phenomenological products of mind rather than an objective reality. But in my view, a serious empirical analysis of the natural foundations of such supernatural beliefs is fair game for science. Being a psychologist, I began to wonder whether there was some way to collect empirical evidence to see whether belief in God and an afterlife is somehow the natural, default state of human consciousness. But to understand why such a thing might have come about, we first must look at how evolution has influenced the human mind.

\section{Evolutionary Psychology}

As psychologists such as David M. Buss of the University of Texas at Austin, Leda Cosmides of the University of California, Santa Barbara, and Steven Pinker of Harvard University have been arguing for more than a decade, not only are our bodies a product of natural selection-for example our opposable thumbs for grasping and our bipedal posture for walking-but our minds bear the thumbprint of evolution 


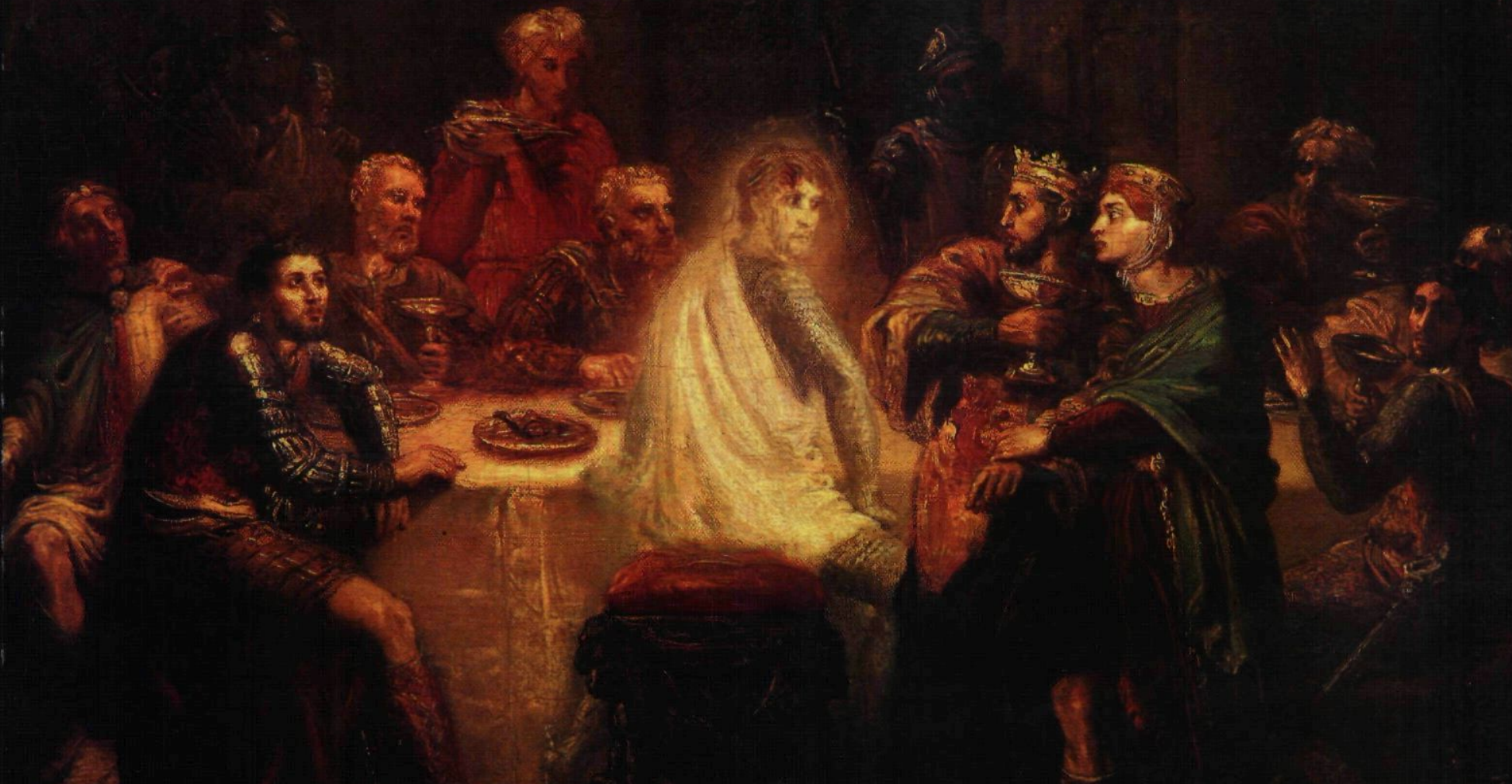

The Art Archive/Musée St.-Denis, Reims/Dagli Orti

Figure 1. In Shakespeare's Macbeth, the ghost of Banquo appears to the king as a rebuke of his murderous ways. Such conjuring-up of supernatural beings may have its roots in the evolution of human minds. The ability to attribute consciousness to invisible, supernatural agents may have come about as a by-product of people's ability to reason about other human minds. But belief in such omnipotent forces could have then increased human genetic fitness by preventing cheating behaviors that could result in social repercussions.

as well. In many cases, the way we think about a particular class of events (the so-called structure of our psychology) reflects why we think that way (the socalled function of our psychology).

Take, for instance, our preference for sweet and fatty foods or our fear of heights and snakes or the fact that we go "coochie-coochie-coo" whenever we see a cute baby. These behaviors are all, according to evolutionary psychologists, caused by unconscious mental forces that helped our ancestors to survive and thrive in the remote past. We may not know why we do, think or feel as we do, but as biologist Richard Dawkins argues in his book The Selfish Gene, from our genes' point of view, this ignorance is entirely moot anyway, so long as we work on their behalf. Behavior is there- fore one of the primary currencies used by natural selection, and it is psychological states that drive behavior.

Recognizing the evolutionary roots of much of human behavior, I began to wonder whether a psychological susceptibility to belief in God is the result of adaptive design. That hypothesis would only make sense if indeed there were behaviors associated with such susceptibility that made us genetically successful. Just as canine teeth evolved to help people rip the flesh off bones, could a belief in God have evolved to help people tear off bits of meaning from an otherwise meaningless existence? Or perhaps God is simply a spandrel-an architectural term (for an ornamental arch) adopted by Stephen Jay Gould and Richard Lewontin to indicate a biologi- cal feature that is passed down part and parcel with another trait and is not on its own a product of natural selection. God might be an accidental by-product of human cognitive evolution, a functionless leftover of the capacity to reason about other human minds in the everyday social world, as cognitive scientists such as Pascal Boyer of Washington University in St. Louis believe. There's a third option, which I favor: that religious belief is an exaptation - a spandrel that turned out to be useful and so was subsequently selected for by evolutionary pressures.

\section{Types of Minds}

One way to assess the impact of evolution on supernatural beliefs is to study different types of minds. In 1996, I made regular excursions to a small town in 


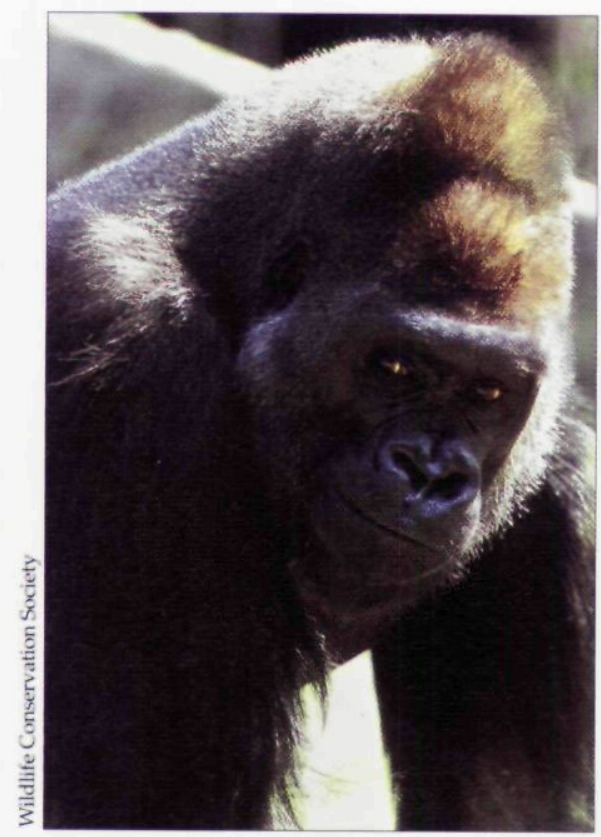

Figure 2. What kind of mind does it take to entertain supernatural beliefs? If evolution has affected supernatural beliefs, variants of these traits should be apparent in minds that have a recent shared ancestry with our own.

Florida called South Hialeah, to see one of the most famous residents of greater Miami. He was called simply "King." Legend has it that he was born, one of a set of twins, somewhere in the dense African rainforest, but when his mother was murdered he was made an orphan and shipped off to the States to perform with his brother in a traveling circus. It was in these early circus days that the ringmaster allegedly had King's teeth knocked out with a hammer.

Now, under a canopy of palms, this 450-pound gorilla with calcified gums leaned imperiously against the wall of his enclosure and stole wary glances at me as I scribbled down my notes. Soon, King's trainer would have him put on his trademark show for shouting schoolchildren, performed three times a day for the past 17 years, in which he would sedately climb on top of a 20 -gallon drum and belly dance for the modest price of a crisp head of lettuce. Over subsequent months, King and I had interactions that were both mutually unsettling and reinforcing: On some occasions, he would pound his chest and charge at me, or projectile-vomit on me; on others he would stick out his enormous feet between the steel bars, inviting me to tickle his plump, rubbery toes, purring with guttural affection. Through all his eclectic behaviors, one question remained in my mind: After a life so profoundly muddled by humans, would King think to ask God why this was his lot in life?

Could King think of God at all? As Darwin stated in The Descent of Man, "There can be no doubt, that the difference between the mind of the lowest man and that of the highest animal is immense.... Nevertheless, the difference in mind..., great as it is, certainly is one of degree and not of kind." If so, then we should find some psychological states in King that are evolutionary variants of human belief in souls or the afterlife.

Although it may be difficult to get King to discuss his thoughts on these matters, there is another way to figure out what kinds of minds are needed to entertain existential beliefs: by seeing how these traits appear in children of different ages. Other mental systems, such as empathy, have been found to emerge piecemeal, with precursory components of the end state coming up gradually during a child's development. If humans are naturally inclined to believe in God and the afterlife, there is good reason to think that children will exhibit signs of these traits before receiving any cultural indoctrination.

This is the question that I explored for my doctoral dissertation, for which I presented children ages 4 through 12 with a puppet show - which we agreed was just a game- that portrayed an innocuous little mouse being eaten by a grumpy alligator. Afterward, I asked the children a series of questions. Now that the mouse was dead, did it miss its mom? Was it still hungry? Was it still angry at its brother? Could it still taste the grass it ate right before it died? Curiously, the younger the child, the more likely he or she was to endow the dead mouse with the capacity to experience various mental states, despite the fact that even preschoolers generally understood that the mouse's body had stopped functioning after death. This is precisely the opposite of the pattern that one would expect to find if the origins of such beliefs could be traced exclusively to cultural indoctrination. In fact, "religious" answers - such as Heaven, God or spirits-among the youngest children were extraordinarily rare. If belief in an afterlife is entirely cultural, older children would have had more exposure and become more socially aligned to prevailing metaphysical beliefs, and therefore would be expected to attribute more traits to the afterlife.
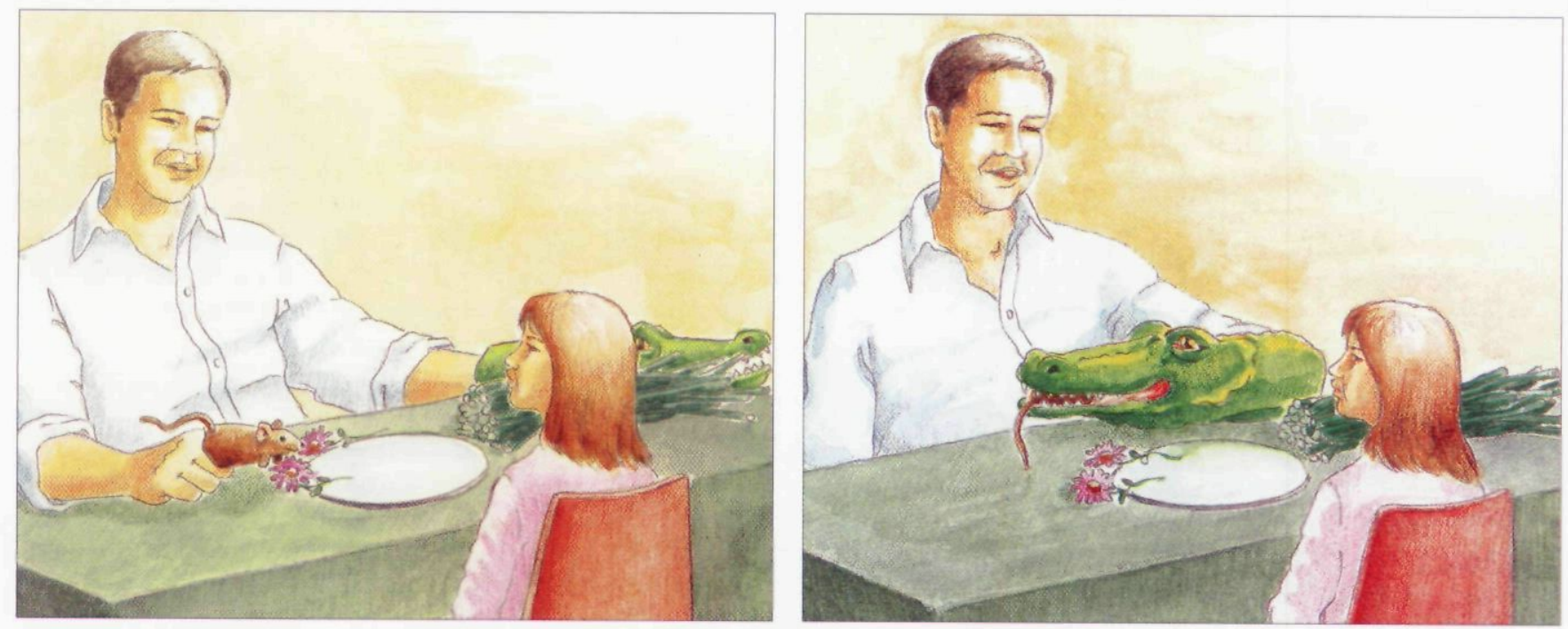

Figure 3. In a study designed to determine whether human beings are born with a tendency to form supernatural beliefs or acquire this ability through cultural exposure, children of various ages were told a story in a puppet show wherein a young mouse is suddenly eaten by an alligator. The children were then asked to describe the mouse's ability to feel or know things after its death (see Figure 4 for results). 
Some of the most striking findings from this study involved a disconnection between closely related bodily and psychological processes. For instance, many of the youngest children reasoned that the dead mouse needn't eat or drink after death while simultaneously reasoning that it retained the capacity for hunger and thirst. Such responses dropped off when children better understood the biology of life. This seemed to show that children have naive theories about psychological functioning after death that initially include all psychological states, which are gradually pruned to a more restrictive range of functioning. For instance, even the youngest children knew that the brain stopped working at death, but most children, even the oldest, refused to say that the mouse stopped loving its mother at death.

\section{The Intuitiveness of the Afterlife}

By claiming that psychological states survive death, or even alluding to this possibility, one commits to a radical form of mind-body dualism, in which each appears to be able to exist without the other. But what, exactly, does the brain do if mental activities can exist independently of it? The devil, it seems, is in the details. In cognitive science, this devil is welcome; indeed, it makes frequent appearances, asking very specific questions. My colleagues and I call this devil reductionism and invite others to watch it play a game of wits with what are perhaps some of their most sacred beliefs. After the devil has had its say, it makes a pretty convincing case. The distinctively human ideas of God, souls and meaning are at once absolutely seductive and yet so disarmingly irrational.

A few years ago, I published the results of a series of interviews with college students who were asked to reason about the fate of the mind after death, much as I had asked the children in the study with the puppet show. The questions I asked were of the reductionist variety: Could a man who was instantaneously killed in a car accident still experience lust? How's his sense of taste? Is he still angry at his wife about their spat the previous night? As expected, those students who reported that they had some belief in God were more likely to attribute mental states to dead agents. The big surprise was that people who categorized themselves as extinctivists - those who stated that personal consciousness is snuffed out entirely at death-often betrayed their real think- ing about the afterlife during the interview. For example, when asked whether the dead protagonist knew that he was dead (a feat demanding ongoing cognitive abilities), one young extinctivist's answer was almost comical: "Yeah, he'd know, because I don't believe in the afterlife. It is nonexistent; he sees that now." Despite himself, this alleged extinctivist was a dualist.

The results of this study, taken with the data from the puppet-show experiment, indicate that, because no one knows what it's like to be dead, people attribute to dead agents the mental traits that they cannot imagine being without. The results also provide evidence that belief in supernatural agents pirates the brain's mental inference systems that are designed to reason about everyday intentional (living) agents. People know that other people have mental traits and actions, even when the other people are not being directly observed. So it may be the default cognitive state to give these traits to unseen dead agents.

Some psychologists, such as Boyer, have put forward the idea that supernatural beliefs arose through culture alone and that religious ideas are pervasive because they are counterintuitive- they violate the mind's understanding of the world, which in fact makes them easier to remember. My view is that afterlife beliefs are the default state, and it is in fact counterintuitive for people to deny them. In the students' and the older children's mental representation of dead agents, some traits were more easily lost than others. The students had to think about twice as long before answering questions about emotional or epistemic (feeling and knowing) states over biological or psychobiological (hearing or hunger, for instance) states after death. To humans, dead agents are therefore not just invisible beings but have a narrower range of experience than in life. Therefore, it seems that it's natural for human beings to reason about death as a transitional state of consciousness, and cultural communication serves to meter-either to enrich or degrade-these intuitive conceptions of the afterlife.

There are several other developmental psychologists who have recently begun investigating the natural foundations of religion using empirical methods from cognitive science, and their results are complementary to what I have found. For example, in a recent study, Valerie Kuhlmeier, a psychologist at Queen's University in Ontario, and her colleagues positioned identical-twin experimenters behind different partitions. This was done in order to test five-month-olds' ability to reason about the law of continuous motion as it applies to human bodies. Infants are known to show surprise at unexpected events by looking at them for longer periods of time. For inanimate objects, infants look longer when the object disappears behind one barrier and then seems to reemerge from

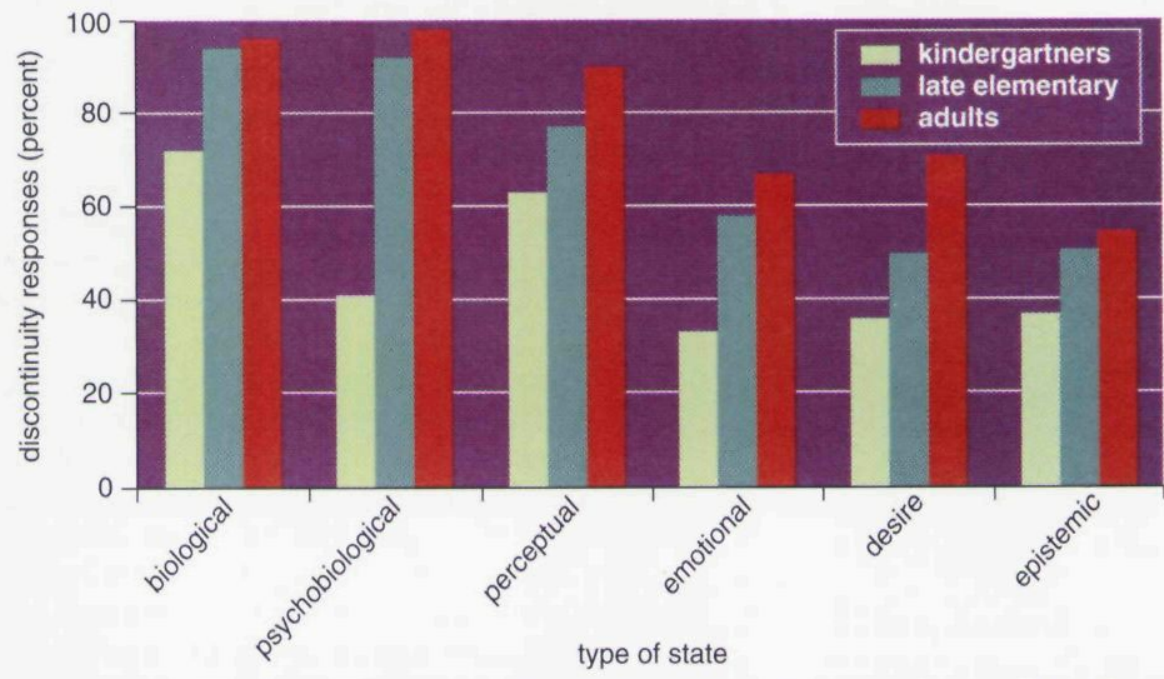

Figure 4. In the experiment described in Figure 3, children of different ages were asked about biological and mental states after death. Adults were asked to answer the same questions for the purpose of comparison. Questions were in biological (need to eat, brain function), psychobiological (hunger, thirst), perceptual (hearing, tasting), emotional (love, anger), desire (wish, want) and epistemic (believe, know) categories. Data indicate the prevalence of discontinuity responses, where respondents denied the dead mouse's ability to experience these states. Younger children were more likely to attribute all abilities to the dead mouse than were older children and adults, the opposite of what would be expected if supernatural beliefs were from cultural indoctrination. 

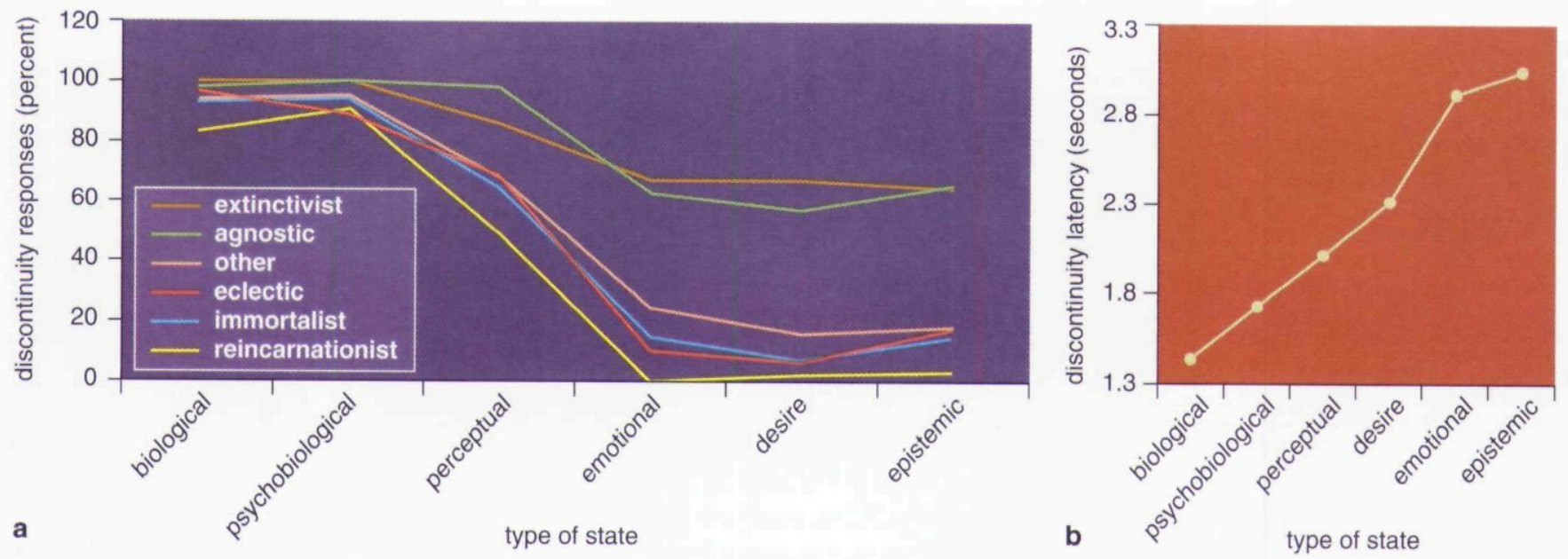

Figure 5. Levels of discontinuity responses for each category of biological or mental traits varied with afterlife belief type: extinctivist (consciousness ends at death), agnostic (uncertain what happens after death), other (consciousness survives death but uncertain what happens afterwards), eclectic (combination of immortalist and reincarnationist beliefs), immortalist (consciousness survives death and lasts forever) and reincarnationist. In all cases, people were most likely to deny that biological traits existed after death and were least likely to deny the persistence of epistemic (knowing) traits (a). However, even about 30 percent of extinctivists paradoxically claimed that desire and epistemic states continue after death. The average amount of time required for participants to deny that dead agents possess traits more than doubled from biological states to epistemic states $(b)$. This result indicates that endowing supernatural agents with mental states is the default of the human mind, and countering this trait takes mental effort.

another nonadjacent barrier. Seeing a person who violates the law of continuous motion, however, five-month-olds are not surprised. The authors speculate that "infants do not readily view humans as material objects" but may first think of people only as intentional agents. An "appreciation that people are just objects may be a developmental accomplishment."

\section{Societal Advantages}

The studies discussed so far have shown that existential beliefs require a certain level of cognitive development to be fully expressed. Afterlife beliefs thus depend on other cognitive systems to exist. Therefore, they are likely not an inde-

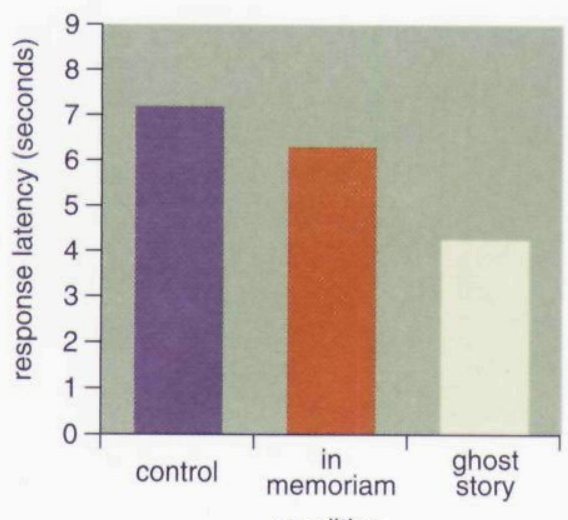

Figure 6. On a competitive task, students who were told of sightings of a ghost were signficantly quicker to resist the temptation to cheat than students who were told only of the recent death of one of the task's creators ("in memoriam") or told no story at all. pendent adaptive trait, but more likely a spandrel or an exaptation. But to theorize further between the latter two possibilities, one needs to determine whether there has been an evolutionary advantage to believing in the supernatural.

Once humans developed speech and societies, selfish behavior such as violence or cheating could be reported. Such behaviors could therefore result in retaliation, such as social marginalization. This punishment would have physical impact: People labeled as poor cooperators might be considered to be poor reproductive partners. Thus, keeping in line became genetically adaptive. But maybe human intelligence couldn't be relied on to follow the rules. In some noone-will-ever-know instances, the threat of detection may appear deceivingly low, so individuals are tempted to profit from cheating tactics. But such temptations would be less attractive if there was a "Santa Claus" effect, where individuals thought that they were constantly being watched by invisible beings. I thus reason that the idea of supernatural observation may serve to counteract such dangerous risk miscalculations, persuading the person to refrain from social deviance and, subsequently, to preserve their genetic fitness.

People in most hunter-gatherer societies have a fear of ancestral ghosts who they think are constantly watching them, but to gather empirical evidence for this theory, my colleagues Katrina McLeod, Todd K. Shackelford and I set up a study of undergraduate students where we tempted them to cheat on a competitive computer task. Students were told that they were evaluating a new test of spatial intelligence, but that there were still some glitches in the program, so occasionally the correct answer would appear on the screen. The students were instructed to immediately hit the space bar to clear the answer. Unbeknownst to them, the answer's appearance was not accidental. We were timing how long it took for students to hit the space bar, so we had a way to measure whether or not the students were cheating on the test. Students were left alone in a room during the task, but one group was told a "ghost story" beforehand-that a graduate student involved in the study had died suddenly, and sightings of his ghost had recently been reported in the testing room. A second group of students was given an "in memoriam" statement at the end of the test instructions, indicating that the test was dedicated to the dead student, but they were not told the ghost story. A third group of students was not told either of these stories. We found that students who were told the ghost story hit the space bar significantly faster than the other two groups, resisting the opportunity to cheat on the task.

So how does all this connect back to God and suffering? If it were evolutionarily advantageous for human beings to believe that omnipotent deities would punish them if they did wrong, they would always do right. It's possible that human logic might have then flipped this around, so that people began to be- 

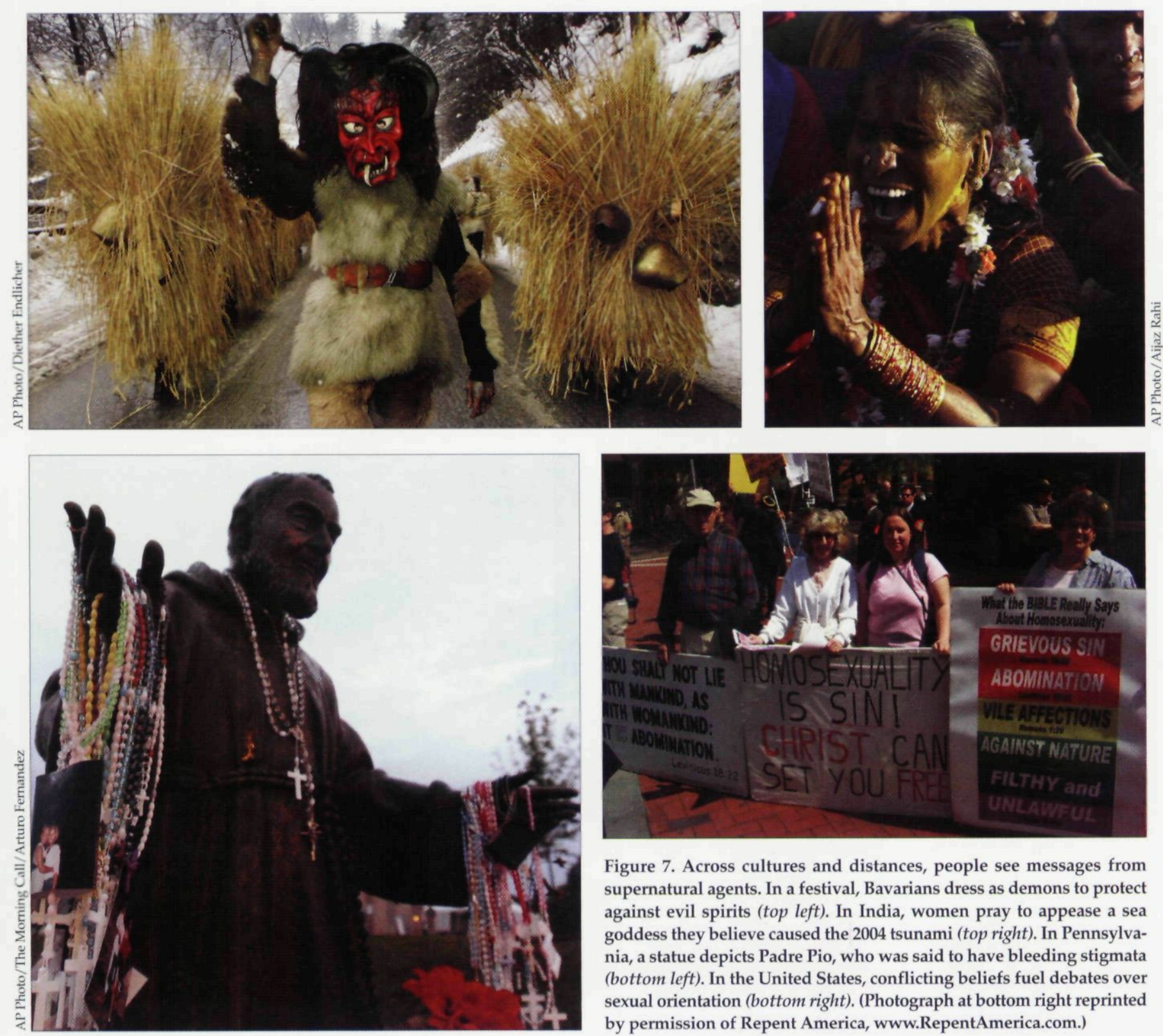

Figure 7. Across cultures and distances, people see messages from supernatural agents. In a festival, Bavarians dress as demons to protect against evil spirits (top left). In India, women pray to appease a sea goddess they believe caused the 2004 tsunami (top right). In Pennsylvania, a statue depicts Padre Pio, who was said to have bleeding stigmata (bottom left). In the United States, conflicting beliefs fuel debates over sexual orientation (bottom right). (Photograph at bottom right reprinted by permission of Repent America, www.RepentAmerica.com.)

lieve by extension that if they do not do wrong, the supernatural being will not punish them. In other words, they believe that they have a "social contract" with the deity, who must adhere to these rules. Indeed, this belief has become so ingrained that if misfortune occurs, some cultures take this to mean that the person has done some unknown wrong.

\section{Signs from Beyond}

If human beings have evolved to believe that dead agents are watching them, it would not be surprising to find that they are looking for messages from their observers, perhaps as reminders that they are indeed under surveillance. And it turns out that communing with the dead does come with well-oiled ease for most people. Granted, it's an ambiguous and one-sided conversation, but for many, the environment is filled with signs from the great beyond.

Cognitive psychology has some explanations for this behavior as well. It turns out that understanding the "messages" of unseen agents is directly related to how we comprehend the minds of other human beings. Consider, for instance, that one day all human beings became hard-core solipsists (a philosophy that denies the existence of other minds). Imagine, say, that everyone was struck down with autism or otherwise lost the capacity to think about other minds, what would happen then? I'd venture that church attendance would reach an all-time low next Sunday. Here then is one key ingredient for belief in God or spirits: an innate disposition to see others not just as ambulant objects or brain-dead sacks of meat, but as think- ing, feeling beings that, just like oneself, are causal agents who do things intentionally. Once children are able to reason about the mental lives of others, developmental psychologists refer to them as possessing a theory of mind.

People and animals behave through their actions, whereas God is believed to "behave" through various events. For example, New Orleans mayor Ray Nagin recently made comments-which he later retracted-suggesting that Hurricane Katrina was God's wake-up call to African-Americans about rampant urban violence: "Surely God is mad at America. Surely He's not approving of us being in Iraq under false pretense. But surely He's upset at black America, also. We're not taking care of ourselves."

In the case of people or deities, we appeal to other minds to explain and pre- 

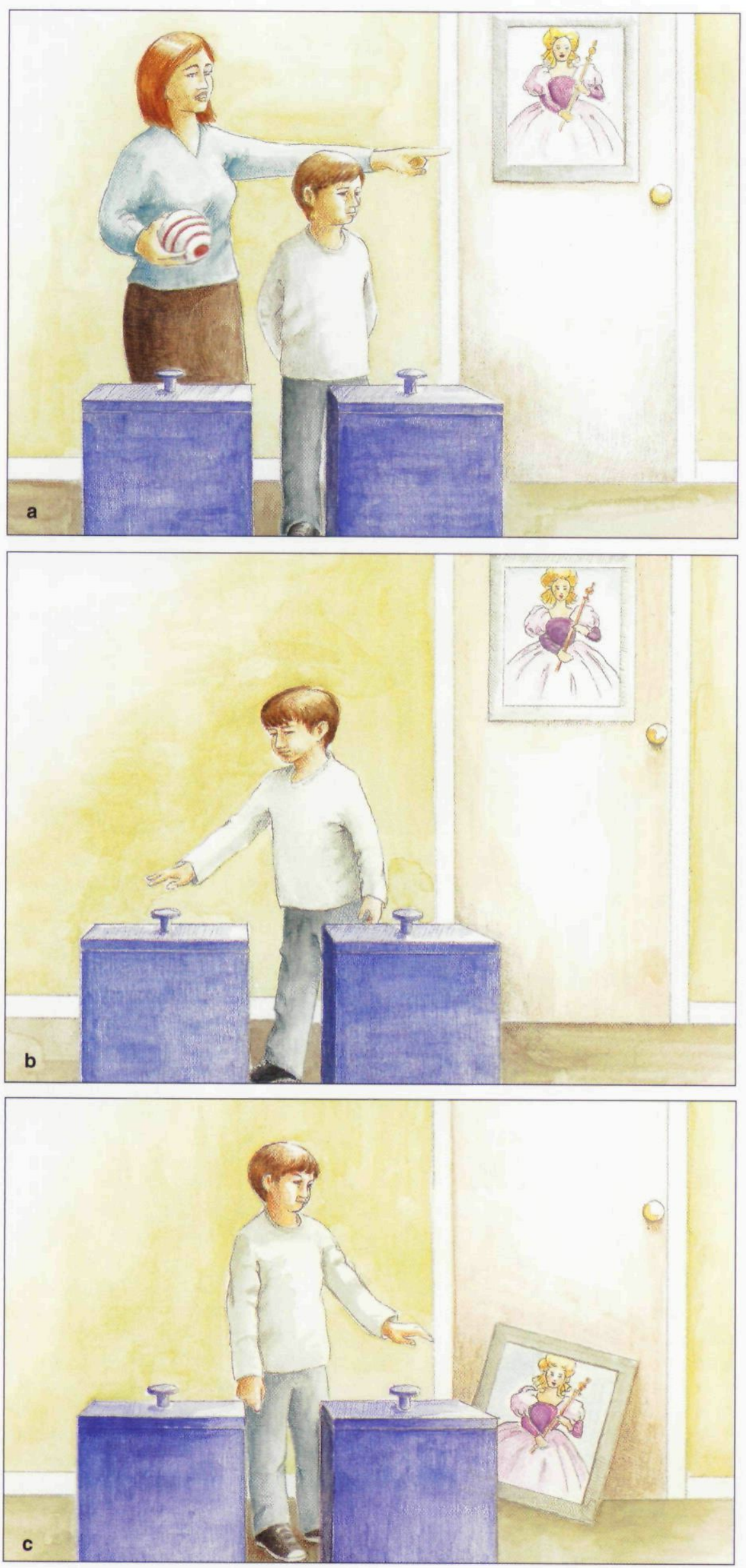

dict behaviors, to understand why others do what they do. Whether you admit it or not, just like the rest of us, you've probably asked yourself the question, "Why me?" If you've answered this by saying "Things happen for a reason," then you're using your everyday social psychology to think about God.

I've experienced firsthand this phenomenon of finding supernatural messages in everyday events. The morning after my mother died, my siblings and I were sitting in her living room, emotionally drained and drowned in our grief. Just then, the wind chimes outside my mother's window started to sound. We looked at one another, and I, the family skeptic, knew exactly what was going through everyone's heads: "That's her! She's telling us not to worry!" I knew because I was thinking precisely the same thing. How strange: Although I didn't believe in the afterlife, I still couldn't help but make such automatic inferences about my dead mother's attempts to communicate with me.

From an experimental psychologist's perspective, this was very inspiring. The ability to see natural events as symbolic should also bootstrap on stages of cognitive development such as a growing ability to read intentions and desires of others. So, naturally, I decided to invite my mother's ghost into my laboratory to see how children of different ages would respond to her antics.

For the sake of the children (and their parents) I had to alter my mother's identity somewhat, calling her "Princess Alice" rather than my "Dead Mother Alice," and telling them that she was a friendly magic princess who could make herself invisible. Also, my research assistants had to give her a helping hand in her attempts to communicate, rigging a picture with a magnetic device so that it would fall "unexpectedly" to the ground, and affixing a remote control adapter to a table lamp so that it would "spontaneously" flash on and off during the experiment.

Figure 8. In an experiment designed to determine whether children will see supernatural messages in everyday events, children were told that a magic, invisible princess would somehow tell them if they chose the box that did not contain the ball (a). Once the children selected a box $(b)$, the princess's picture was made to fall off the wall. Only the oldest children in the study interpreted the picture falling as a message from the princess and changed their selection of boxes as a result $(c)$ (see Figure 9 for results). 


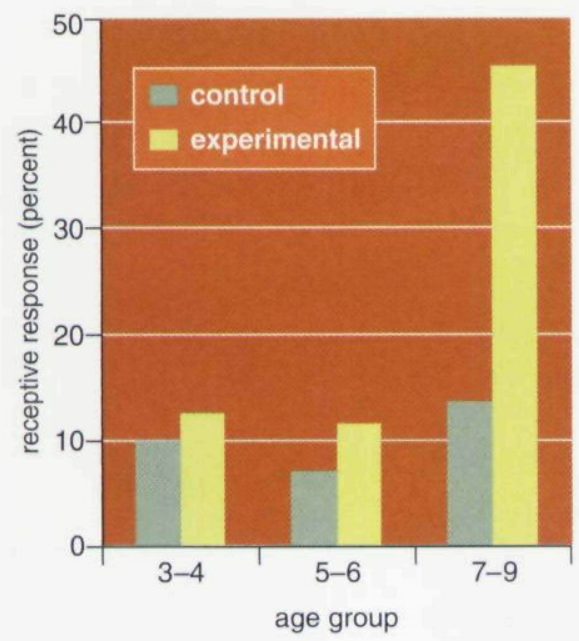

Figure 9. Only the oldest children who were told the story of Princess Alice (experimental) saw the picture falling as a message from Princess Alice that they had made the wrong choice in a guessing game. Children in any age group who were not told any story (control) did not switch their choice.

After being told that Princess Alice would help them play a game, in which they were to guess the location of a ball hidden inside one of two boxes, "by telling you, somehow, when you pick the wrong box," only the oldest children in the study, the seven-year-olds, chose the opposite box in response to the unexpected events. One of these second graders even thought that the bell chiming in the nearby university clock tower was Princess Alice "talking" to him. The fiveyear-olds, too, thought it was Princess Alice doing these things, but they didn't see any communicative attempts in the events (maybe she thought the picture just looked better on the ground?), and so they stuck with their initial choice. They could detect agency, but not meaning, in the unexpected events. The threeyear-olds only shrugged their shoulders, or gave physical explanations for the events, such as the picture not being sticky enough to stay on the door.

Unlike the puppet-show study, the children here were more susceptible to attributing abilities to supernatural agents because in this case, it required that they had developed cognitively to have what's called second-order reasoning. They had to be able to understand that "Alice knows that I don't know where the ball is" in order to be susceptible to the "hidden messages."

So, just what was my mother trying to tell me from beyond the grave, anyhow? Although it's open for debate, I interpreted her message as follows: When combined with a cognitively ripe enough mind, and when the emotional climate is just right, there is no shape that evidence cannot assume in order to tempt the most recalcitrant of skeptics. In the words of one such wide-eyed little disbeliever who had just seen the lights inexplicably flicker: "I thought invisible was just make-believe; maybe it is real!"

Some investigators, such as Justin Barrett of the Institute of Cognition and Culture in Belfast and Scott Atran of the University of Michigan, theorize that there are evolutionarily advantageous reasons for such a ready susceptibility to believing that any activity in the environment was actively caused by some kind of agent. It is better for children to mistake a branch falling in the forest for a predator than it is for them to misinterpret signs of danger as a product of the weather, for instance. Such hypervigilance mechanisms kept people alert and ready, but they may also make them overly inclined to attribute a natural event as some kind of intentional act.

\section{Increasing Impact}

It is clear that when it comes to the big questions in life, our brains have evolved so that science eludes us but religion comes naturally. There are still many pieces to fill in on the big picture of human cognitive evolution as it relates to supernatural beliefs. But I believe that this area of research could have a positive impact on society. Bringing such discussions into a context where they could be understood by a large range of people could have immense benefits in decreasing the divide that many people feel separates science from everyday life.

There are a number of scholars currently working on novel evolutionary theories of religion, but there are also a lot of exciting discoveries taking place in this field that have yet to strike the right chord with the educated public. I recently taught a graduate seminar on this topic by starting off with Boyer's excellent book, Religion Explained, which uses numerous anthropological examples to account for the origins of religious thought. One student told me, "It's all good in theory, and maybe it does explain religion, but I can't see what it has to do with my belief in God." Although it is absolutely critical to study a variety of cultures and different species if one aims to illustrate the commonalities of behavior across seemingly diverse groups, researchers in this area should increasingly begin talking about God and Western souls rather than, for instance, the ancestral spirits of the Tupi peoples, or the concept of evil among the Igbo of Nigeria.

If one could answer what have traditionally been solely philosophical questions using testable means and place the results in a plausible theoretical context, areas that have historically been out of bounds for scientists could be rightfully claimed by psychological science. Despite the social quagmire surrounding all things religious, the rigorous study of supernatural beliefs could be necessary for a complete understanding of human cognitive development. I believe that these new applications of cognitive science are particularly important to human understanding. Perhaps this field of experimental research has the potential to teach us-with minimal human bias-how we really, truly fit as individual "souls" in this world.

\section{Bibliography}

Bering, J. M. 2002. The existential theory of mind. Review of General Psychology 6:3-24

Bering, J. M. 2002. Intuitive conceptions of dead agents' minds: The natural foundations of afterlife beliefs as phenomenological boundary. Journal of Cognition and Culture 2:263-308.

Bering, J. M. In press. Children's attributions of intentions to an invisible agent. Developmental Psychology.

Bering, J. M. In press. The folk psychology of souls. Behavioral and Brain Sciences.

Bering, J. M., and D. F. Bjorklund. 2004. The natural emergence of reasoning about the afterlife as a developmental regularity. Developmental Psychology 40:217-233.

Bloom, P. 2002. Descartes' baby: How the Science of Child Development Explains what Makes us Human. New York: Basic Books.

Boyer, P. 2001. Religion Explained: The Evolutionary Origins of Religious Thought. New York: Basic Books.

Buss, D. M., M. G. Haselton, T. K. Shackelford, A. L. Bleske and J. C. Wakefield. 1998. Adaptations, exaptations and spandrels. American Psychologist 53:533-548.

Cosmides, L., and J. Tooby. 1997. Evolutionary psychology: A primer. On-line document: http://www.psych.ucsb.edu/research/cep/ primer.html [accessed January 3, 2005].

Dawkins, R. 1976/1989. The Selfish Gene (new ed.). New York: Oxford University Press.

Freud, S. 1961. The Future of an Illusion. New York: W. W. Norton \& Sons.

Pinker, S. 2002. The Blank Slate: The Modern Denial of Human Nature. New York: Viking.

For relevant Web links, consult this issue of American Scientist Online:

http://www.americanscientist.org/ IssueTOC/issue/821 
Copyright of American Scientist is the property of Sigma XI Science Research Society and its content may not be copied or emailed to multiple sites or posted to a listserv without the copyright holder's express written permission. However, users may print, download, or email articles for individual use. 